\title{
LA ESTRUCTURA CORPORATIVA EN LA AGRICULTURA ESPAÑOLA
}

\author{
Eduardo Moyano Estrada \\ y Manuel Pérez Yruela \\ (Universidad de Córdoba)
}

\section{INTRODUCCION}

Nuestra aportación va a consistix en una breve exposición del contenido de una investigación más amplia presentada como tesis doctoral en la Universidad de Córdoba con el título de «Corporatismo y Agticultura: aproximación al caso español» (E. Moyano, 1982). Nos centraremos en tres aspectos de Ia citada investigación, que constituirán el contenido bá sico de las líneas que siguen. Primero, plantearemos brevemente el debate sobre el corporatismo o corpotativismo y situaremos en él la posición teórica de la que hemos partido para la investigación desarrollada. Segundo, formularemos de forma esquemática las proposiciones fundamen* tales del marco teórico elaborado para dar explicación a la manifestación del fenómeno corporatista en la agticultura. Y, finalmente, tratatemos lo que han sido las relaciones entre las Organizaciones Profesionales Agrarias (OPAS) y el Ejecutivo en las negociaciones anuales de precios agrarios celebradas en España durante el período de transición democrática, por haber sido dichos encuentros el caso más típico de corporatismo que ha podido observarse en la agticultura española. 


\section{ALGUNAS REFLEXIONES EN TORNO AL DEBATE CORPORATISTA}

Aun sin entrar de lleno en el debate sobre el «corporatismo» iniciado ya a principios de los setenta y enriquecido con gran número de aportaciones procedentes de posiciones intelectuales diversas, ${ }^{1}$ sí es conveniente situar en dicho debate la posición teórica de la que se ba partido para llevar a cabo la investigación antes citada.

Una revisión de las más importantes aportaciones existentes en el debate corporatista permite observar cómo éstas se centran casi exclusivamente en los aspectos económicos del corporatismo, concretamente en las prácticas de la negociación y del pacto entre gobiernos, patronales y sindicatos sobre cuestiones relacionadas con la actividad industrial. La manifestación del corporatismo en otras esferas de la vida social, como la política, o en otras actividades económicas, como la agricultura, no ha sido, por lo general, motivo de interés en dicho debate.

Esta restricción de los estudios corporatistas plantea una doble problemática que afecta negativamente al progteso científico logrado en el debate. En primer lugar, está el problema del objeto de análisis, ya que la utilidad de la perspectiva corporatista para estudiar aspectos relacionados con el proceso de articulación de intereses a través de grandes organizaciones en esferas diferentes de la económica o en actividades distintas de la industrial, es puesta en duda al comprobarse que los conceptos de esa perspectiva no son aplicables al objeto que se desea analizar sino que, por el contrario, su fertilidad analítica se reduce a objetos de un ámbito más restringido. Ello obliga a los investigadores centrados en otras esferas de la vida social a elaborar nuevos matcos teóricos, lo que supone acuñar nuevos conceptos y definiciones e, incluso, nuevas tipologías.

Así, surge un segundo problema, cual es la ausencia de acuerdo general sobre una definición del corporatismo. Existen, ciertamente, importantes definiciones del tema, unas más elaboradas que otras, pero todas ellas son fruto de aproximaciones al corporatismo desde posiciones alejadas, que han impedido un cierto nivel de consenso teórico. ${ }^{2}$ Ambos problemas, el

1. Dado que otras aportaciones a este coloquio se centran en el debate corporatista, analizando sus más importantes colaboraciones y posiciones teóticas, renun. ciamos a la posibilidad de exponer aquí una nueva revisión del mismo.

2. Buena muestra de la falta de acuerđo general sobre una definición de corporatismo puede observarse analizando las definiciones enunciadas por Schoitter, Winkler o Pasitch, por citar las más significativas. Mientras que para ei primero el corporatismo es un sistema de tepresentación de intereses, para Winkler es un sistema económico, distinto del capitalisno y del socialismo, y para Panitch es una estructura política dentro del capitalismo avanzado. 
del objeto de análisis y el de la definición, están relacionados. En efecto, la centralización del análisis sobre objetos limitados ha impuisado a los investigadotes a la formulación de definiciones restringidas del corporatismo que, en el mejor de los casos, sólo tienen validez para estudiar la manifestación concreta del fenómeno de una maneta parcial.

Por todas esas razones, la posición teórica de la que aquí se parte es la de una concepción general del corporatismo que no reduce su objeto de análisis a una esfera concreta de la vida social, sino que pretende captar las nuevas formas de articulación de intereses a través de grandes organizaciones que pueden observatse, con mayor o menor relevancia, en todos los ámbitos de las sociedades capitalistas avanzadas. Desde esta posición teórica, el corporatismo se concibe como un fenómeno característico de las sociedades capitalistas avanzadas, pero no exclusivo de ellas, por el cual las grandes organizaciones de intereses - corporaciones-ostentan un cierto grado de hegemonía como elementos vertebradores del orden social. ${ }^{3}$ Dicha hegemonía se entiende como el resultado de un proceso de corporatización social, es decir, de atticulación de intereses a través de grandes organizaciones, en el que han intervenido diversos factores: Ia creciente división del trabajo, la concentración económica, las nuevas funciones del Estado, la implantación del modelo de sociedad de consumo, la división del trundo en bloques hegemónicos, la consolidación de los sistemas sociales imperantes, etc., más algunas condiciones técnicas que la han hecho posible.

Asimismo, en dicha posición teórica se admite que el corporatismo adquiere una dinámica propia en cada área o sector de actividad, de acuerdo con las peculiaridades de los procesos productivos que en ellos tienen lugar y de acuerdo con sus estructuras sociales. No obstante dicha heterogeneidad, puede establecerse la tendencia general a que en cada área o sector de actividad se produzca una concentración de poder en unos cuantos centros de decisión, constituidos por las cúpulas de sus respectivas piránides de representación y sometidos a un alto grado de interde-

3. La posición teórica del corporatismo utilizada en este trabajo ha sido ya formulada por S. Giner y M. Pérez Yruelz en su libro La sociedad corporativa (Madrid: CIS, 1979). Los conceptos de «corporación», «proceso de corporatización» y «expansión corpotativan han sido acuñados por estos autotes y expuestos en la obra ya mencionada, por lo que el uso que aquí se hace de los mismos ha procurado ajustarse a la definíción entnciada por los citados investigadores. De entre dichos conceptos conviene señalat que por "corporación" se entiende una organización de intereses caracterizada por: la pretensión de ser monopolio representativo, poseer un alto grado de especialización funcional y lievar a cabo una intensa coordinación imperativa sobre sus miembtos, una interna división de las tareas organizativas y una jerarquización explícita y detallada. 
pendencia. ${ }^{4}$ Estas cúpulas decisotias entran en interrelación con las de otras áreas o sectores de actividad, estableciendo nuevos centros de decisión a un nivel superior y, así, sucesivamente. En el vértice de este proceso piramidal se encuentra la cúpula del Estado como gtan corpotación que ejerce una coordinación imperativa sobre los diversos actores, con el objetivo de reproducir el sistema social imperante con el menor coste posible. Sin embargo, en el proceso de interrelación de las diversas corporaciones no se da un equilibrio de poder e influencia entre ellas, ni el Estado juega un papel reutral en el mismo, sino que en dicho proceso se tefiejan los sistemas de desigualdad social y económica dominantes, lo que hace que -el corporatismo no pueda garantizar la estabilidad y la reproducción del sistema social al estar sus instituciones de representación/mediación permanentemente sometidas a los conflictos emanados de la propia naturaleza de dicho sistema. ${ }^{5}$

El corporatismo no elimina, por tanto, los conflictos sociales inherentes a la sociedad pero los modifica en la forma y en el contenido, radicando ahí, precisamente, su importancia como elemento fundamental de reestructuración del orden social. Así, el corporatismo hace que la dinámica conflictiva no tenga ya lugar mediante un enfrentamiento directo entre los diversos grupos de intereses, sino que esté mediatizada a través de otganizaciones representativas intensamente corpotatizadas, de manera que, en la práctica, el confficto se reduce a una oposición entre las cúpulas dirigentes de los grupos sociales en liza, oposición que puede manifestarse de muy diversas formas.

En resumen, desde la posición teórica aquí utilizada, el cotporatismo no es sólo la práctica de la negociación entre gobierno, sindicatos y organizaciones patronales, sino un fenómeno más amplio de reestructuración del orden social a través de grandes organizaciones de intereses, intensamente corporatizadas y fuertemente intertelacionadas. Fenómeno pre-

4. En la esfera económica, por ejemplo, y dentro de ella, en el sector industrial, el poder se concentra en las cúpulas de las organizaciones empresatiales y de los sirdicatos, las cuales están sometidas a un alto grado de interdependencia y participan en centros de decisión de diverso rango.

5. La permanente conflictividad a que se ven sometidas las instituciones corporatistas de representación/mediación introduce en su seno una situación de inestabilidad que afecta a la funcionalidad del corporatismo como elemento de estructuración del orden social en el capitalismo avanzado. Un análisis más exhaustivo sobre este tema puede verse en el artículo de G. Lehmbruch, "Liberal Corporatism and Party Government', publicado en P. Schmitter y G. Lehmbruch, Trends toward Corporatist Intermediation (Londres: Sage, 1979) y en el de L. Panitch, «Trade Unions and the Capitalist States, publicado en New Left Review, enero-marzo, 1981, pp. 21-43. 
sente en todos los ámbiìos de las sociedades capitalistas avanzadas, aunque con características peculiares en cada uno de ellos.

\section{EL CORPORATISMO AGRARIO'}

La manifestación del fenómeno corporatista en la agricultura de los países capitalistas avanzados adopta unos rasgos característicos. Bien es cierto que, al igual que en otros sectores de actividad, en la agricultura se produce una reducción del pluralismo representativo y la configuración de una estructura corporatista basada en grandes organizaciones de intereses. Pero a diferencia de otros sectores, la estructura corporativa de la agricultura presenta una mayor dispersión, ya que existe un mayor número de organizaciones de intereses en liza y una mayor debilidad de éstas, tanto a nivel macro como microsociológico, y que estas organizaciones tienen una estructura interna débilmente corporatizada y están sometidas a una permanente interferencia de agentes externos, con los que mantienen estrechos lazos de dependencia. Asimismo, la estructura corporativa agraria, aun presentando los rasgos típicos de un corporatismo de tipo pluralista, está sujeta a un alto grado de intervencionismo estatal que no tiene comparación con las estructuras corporativas de otros sectores.

Para dar explicación a esta peculiaridad del corporatismo agratio, la investigación ya citada elaboró un marco teórico constituido por las proposiciones que a continuación se exponen de una manera hasto esquemática:

a) En el ejercicio de su influencia en los centros de decisión donde se formulan las líneas directrices de la política agraria, las organizaciones representativas de los diversos intereses agrarios muestran una gran debilidad frente a organizaciones de intereses no agrarios y frente a la $\mathrm{Ad}$. ministración estatal,

b) Esta debilidad puede ser explicada en base a un conjunto de factones cuya naturaleza es doble. Por un lado, están los factores de natura. leza económica, referidos todos ellos a los diversos aspectos de la subordi. nación de la agricultura en el sistema económico de los países capitalistas avanzados. Subordinación manifestada, entre otras cosas, por la pérdida

6. Este apartado hará referencia al ptoceso de articulación de intereses de los distintos grupos de agricultores existentes en la sociedad rural, excluyendo del aná. lisis a los trabajadores asalariados, cuyas peculiatidades exige un tratamiento aparte. 
de hegemonía de la agricultura como actividad productiva, ${ }^{7}$ por su depen. dencia finarciera y por su integración dependiente en el sistema agroalimentario.

c) Por otro lado, están los factores de naturaleza social, relacionados de forma general con las dificultades que encuentra el proceso de articulación de intereses en la sociedad rural para crear organizaciones fuertes y bien consolidadas que actúen como interlocutores válidos e idóneos ante la Administración estatal y ante otras organizaciones no agrarias. Esta dificultad radica en el becho de que en la sociedad rural el proceso de articulación de intereses puede verse como un proceso dialéctico entre dos tendencias: una, que favorece la dispersión de los agricultores en vatias organizaciones de intereses y, otra, que hace tender el proceso bacia la concentración de todos ellos en una sola organización fuertemente teivindicativa de los intereses del sector agratio como un todo homogéneo.

Entre los factores de dispersión pueden destacarse los siguientes: por un lado, la heterogeneidad de la agricultura desartollada, tanto a nivel de la diferente orientación productiva entre las explotaciones agrarias como dentro de cada explotación, que dificulta la conciliación de problemáticas distintas en un programa reivindicativo común y favorece la aparición de organizaciones sectoriales; por otro lado, las peculiaridades de la actividad productiva agrícola y sus condicionantes físicos - aislamiento y dispersión geográficos, fuerte dependencia del agricultor del ciclo productivo de su explotación, etc.--, que dificultan la construcción de una infraestructura organizativa sólida y bien articulada que tecoja eficazmente las demandas heterogéneas del sector; finalmente, hay que considerar entre esos factores de dispersión Ia estructura de la propiedad de la tierra y las formas de tenencia, al plantear problemáticas específicas y diferenciadas a los pequeños, medianos y grandes agricultores, así como a los propietarios y arrendatarios.

Contrarrestando los factores de dispersión están presentes ciettos elementos de carácter sociocultural e ideológico que hacen que el proceso de articulación de intereses tienda hacia la concentración. Unos elementos pueden estat reiacionados con los sistemas de patronazgo y demás lealtades primordiales que, tradicionalmente, han caracterizado las relaciones sociales en el medio rural y que, en el caso de la agricultura desarrollada,

7. Indicadores de esa pérdida de hegemonía de la agricultura como actividad productiva serían el menor porcentaje de la población activa agraria en la población activa total, su menor aportación relativa al PIB o el menor peso relativo de los intercambios comerciates agrarios en el comercio exterior. 
no han desaparecido sino que se manifiestan de forma diferente. ${ }^{8}$ Otros, sin embargo, pueden estar relacionados con el impacto que la ruptura del orden tradicional en el medio rural y la pérdida de hegemonía del sector agrario en el sistema económico general han tenido sobre las conciencias colectivas de los diversos grupos componentes de la estructura social rural, quienes adoptan actitudes comunes de recelo hacia agentes externos identificados con la sociedad urbano-industrial y en los que los agricultores personalizan las causas de su sometimiento a intereses que escapan de su propio control. Estas actitudes culminan en una tendencia generalizada a que los diversos grupos de agricultores se integren en una especie de «frente agrario» para defender los intereses de la agricultura como un todo, frente a otros sectores económicos.9

d) A pesar de las dificultades que encuentra el sector agrario para articular por sí mismo sus intereses en otganizaciones representativas fuertes y bien consolidadas, el buen funcionamiento del sistema económico y social en el capitalismo avanzado exige que del sector surjan interlocutores válidos e idóneos para participar en las instituciones corporatistas de representación/mediación características de este tipo de sociedades. Por eilo, el proceso de corporatización en la agricultura se ve permanentemente interferido por otras dinámicas corporatistas, produciéndose así una especie de corporatización «desde fuera» del sector agrario en el que intervienen elementos del corporatismo estatal, así como de los corporatismos que tienen lugar en la esfera política y en esferas económicas distintas de la agticultura, persiguiendo todos ellos imponer en el sector agtatio una estructura corporativa acorde con los objetivos particulares de los grupos que interfieren.

Así, el corporatismo estatal interfiere a través de agentes corporatizantes, como las Cámaras Agrarias, o bien utilizando la baza del reconocimiento como interlocutores a organizaciones de carácter genetal y ámbito estatal o ptomoviendo nuevas organizaciones, Esta interferencia ha

8. Un ejemplo de esos factotes de concentración puede observarse en la integración de pequeños agricultores en organizaciones dominadas por grandes empresarios agrícolas, explicada, entre otras cosas, por la ted de dependencias económicas establecidas entre estos dos grupos sociales, haciendo que el grupo en posición subordinada se vea obligado a aceptar las condiciones impuestas por el grupo dominante si desea continuar secibiendo los benefucios de dicha relación depenđiente.

9. Esa tendencia a la creación de un «frente agratio» en el terreno sindical se traslada en determinadas circunstancias al terreno político con la creación de «partidos agraristasn. Para un análisis del comportamiento político de los agricultores en el seno de las democracias occidentales puede verse Juan J. Linz, «Patrern of Land Tenure, Division of Labor and Voting Behaviour in Europe» en «Comparative Politics», abril, 1979, pp. 365-430. 
perseguido objetivos tales como neutralizar la posible contestación a determinadas medidas de política agratia, interfiriendo la participación y la representación de las organizaciones agrarias en los centros de decisión, o como también contrarrestar los factores de dispersión sin llegar nunca a favorecer la tendencia a la creación de un "frente agrario», que representaría una amenaza para el logro de los objetivos de la política econó. mica general. La interferencia realizada por el corporatismo político no estatal se refleja en el objetivo de los partidos políticos por crear sus bases de apoyo en la sociedad rural ante las sucesivas contiendas electorales. ${ }^{10}$ Por su parte, el corporatismo económico no agratio interfere con el propósito de canalizar o neutralizar las reivindicaciones de los diversos grupos de intereses agratios por cauces que no pongan en peligro los in. tereses de los nuevos sectores hegemónicos. ${ }^{11}$

Los supuestos contenidos en las proposiciones anteriores - subordinación económica, débil corporatización interna, interferencia de otras estructuras corporativas- constituyen, en defnitiva, los elementos básicos del marco teótico elaborado para analizar la manifestación del fenómeno corporatista en la agricultura de los paises capitalistas avanzados. Tales proposiciones deberán ser contrastadas empíricamente con el estudio de casos concretos para comprobar su validez como elementos explicativos de los hechos sociales que son objeto de atención en el debate en torno al corporatismo.

10. La estrategia empleada por los partidos políticos para interferir en el proceso de articulación de intereses que tiene lugat en la agricultura, varía desde la promoción de organizaciones de agricultores ideológicamente afines hasta la colocación de sus militantes en los puestos directivos de organizaciones ya constituidas. En la elección de la oportuna estrategia por parte de los particos políticos intervienen variables tales como la posición ideológica de cada partido y su correspondencia en la estructura social retal, su capacidad de infuencia en los centros políticos de decisión - los recursos utilizados para ejercer dicha capacidad.

11. La interferencia del corporatismo económico no agrario se analiza de forma exhaustiva en la investigación ya citada, donde se formula, incluso, una tipología de la fnisma, expresada en estas tres categorias de interferencia: extraorganizativa, intraorganizativa e jnterorganizativa. 


\section{EL ANALISIS DE UN CASO EMPIRICO: LAS NEGOCIACIONES ANUALES DE PRECIOS Y DEMAS MEDIDAS DE POLITICA AGRARIA ENTRE LAS OPAS Y EL EJECUTIVO EN ESPAÑA}

Durante la transición democtática en España las relaciones entre las Organizaciones Profesionales Agrarias (OPAS) y el Ejecutivo han tenido como punto culminante las negociaciones anuales para determinar los precios de los productos agratios sometidos a regulación oficial y para fijar otras medidas de política agraria no circunscritas al área de la politica de precios. Estas reuniones han constituido el caso más significativo de la manifestación del corporatismo en la agricultura española, plasmándose en ellas las peculiaridades de dicho fenómeno y representando, por tanto, un interesante laboratorio para contrastar empíricamente algunos de los elementos contenidos en el matco teórico anteriormente expuesto.

\subsection{Claves TÉCNICAS dE LAS NEGOCIACIONES}

Para comprender la dinámica que ha tenido lugar en las denomina das «negociaciones de precios agrarios» entre las OPAS y el Ejecutivo es. necesario plantear, previamente, las claves técnicas que están presentes en dichas reuniones. Con estas claves técnicas se quiere dar tespuesta a cuestiones tales como: por qué se ha negociado, quiénes han sido los actores participantes, dónde se han llevado a cabo esas negociaciones, qué y cómo se ha negociado. Estas respuestas permitirán abordar, más adelañ te, con un mayor rigor, el aspecto sindical de dichas negociaciones y su dinámica a lo largo del período considerado. ${ }^{12}$

En primer lugar, hay que señalar que la intervención del Estado en la agticultura es tanto una exigencia del propio sector agratio como un imperativo del sistema económico y para llevar a cabo esa intervención el Estado, a través de sus oportunos organismos, aplica determinados instrumentos de política agraria. La política de precios es uno de esos instru. mentos y dado su carácter de breve temporalidad, al tener que ajustarse a las peculiaridades de cada campaña agrícola en contraste con la política

12. Como se ha seffalado, el período considerado en esta investigación es el de Ia transición democrática iniciada con el advenimiento de la monarquía parlamentaria y culminada, según el criterio de muchos investigadores que aquí se comparte, con la victoria del PSOE en las elecciones de octubre de 1982. Por tanto, las negociaciones de precios celebradas en 1983 no son objeto de análisis, aunque comparten muchas de las características manifestadas en las anteriores. 
de estructuras que tiene una perspectiva de mayor alcance temporal, es lógico que sea necesaria su revisión, al menos anuai, habiendo constituido, por ello, el tema central de las citadas negociaciones.

Sin embargo, la existencia en España de negociaciones entre las OPAS y el Ejecutivo sobre la política de precios es un caso, en cierto modo, excepcional, que ha de explicarse por las características específicas del proceso de reforma. ${ }^{13} \mathrm{El}$ comienzo de este tipo de reuniones fue resultado de un acuerdo contenido en los Pactos de la Moncloa (1977), pero una vez iniciadas, y dado el escaso curaplimiento que el conjunto de dichos pactos tuvieron por parte del Gobienno de UCD, la continuidad de las mismas debe explicarse, en gran medida, por una especie de simbiosis entre las OPAS y el Ejecutivo. Por un lado, a través de esas negociaciones, el Gobierno, y concretamente el Ministerio de Agricultura, legitimaba su política al lograr la participación, con más o menos influencia, de las organizaciones agrarias en la formulación de la misma. Por otro lado, las OPAS vefan en esas reuniones su teconocimiento como interlocutores del sector agrario y las valoraban no sólo por la influencia ciertamente escasa que a través de ellas pudieran ejercer sobre el contenido de la polí. tica de precios sino porque la existencia misma de las citadas reuniones y su consiguiente impacto en la opinión pública, a través de los medios de comunicación, les daban razón de ser ante los agricultotes en una etapa inicial de grandes dificultades para su implantación, dadas las actitudes débilmente corporatistas de éstos.

En segundo lugat, los participantes en esas negociaciones variaron de unas reuniones a otras. Así, en la negociación de 1978, cuyas reuniones se celebraron antes de las elecciones a Cámaras Agratias, además de los representantes de la Administración, presididos por el propio ministro de Agricultura, participaron cuatto organizaciones profesionales agrarias: COAG (Coordinadora de Organizaciones de Agricultores y Ganaderos del Estado Español), CNAG (Confederación Nacional de Agricultores y Ganaderos), CNJA (Centro Nacional de Jóvenes Agricultores) y ARA (Asociación Regionalista Agraria), es decir, una del sindicalismo "de clase», otra de sindicalismo «empresarial» y dos del «reformista», respectivamente. ${ }^{14}$ En la de 1979, tras unas elecciones a Cátoaras que clarificaron, en

13. En la CEE la política de precios agrarios la fija el Consejo de Ministros sin entablar negociaciones previas, ni siquiera formales, con las organizaciones de agricultores integzadas en el COPA, imitándose a recoger la información que aquellas quieran transmitirle sobre sus puntos de vista acetca de lo que debiera ser dicha política.

14. El parsotama sindical agratio configutado dutante la transición democtática en España, en lo que se refiere a los agricultores, ha sido estudiado de forma exhaustiva en la investigación citada, habiéndose elaborado una tipología de las Organiza- 
gran medida, el panorama sindical agrario y cuyos resultados sirvieton de indicador de la representatividad, participaron, por parte de las OPAS, dos organizaciones «de clase» -COAG y FTT (Federación de Trabajadores de la Tierra)-, una «empresarial»-CNAG- y dos «reformistas» -CNJA y UFADE (Unión de Federaciones Agrarias de España)—, mientras que la representación de la Administración estuvo también presidida por el ministro de Agricultura, Lamo de Espinosa. Después de la excepcionalidad de 1980, año en el que no hubo en realidad negociaciones glo bales de precios agxarios sino que las OPAS fueron convocadas a participar en una especie de "mesas consultivas» sobre cada producto, las reuniones entre las OPAS y el Ejecutivo se institucionalizarían por el decreto de 20-XII-1980 en el que se acuerda la constitución del Consejo General del FORPPA (Fondo de Ordenación y Regulación de Precios y Productos Agrarios). A partir de este momento, se introdujeron modificaciones im. portantes en los actores de las siguientes reuniones. Por una parte, la representación de la Administración ya no fue presidida por el ministro de Agricultura sino por el presidente del FORPPA; por otra parte, a los cinco representantes de las OPAS se añadieton representantes de otros sectores privados, como Cooperativas, Agrupaciones de Productores Agrarios, Sociedades Agrarias de Transformación, Cámaras Agrarias y de Co mercio, Consumidores y Amas de Casa, así como de las industrias alimen-

ciones Profesionales Agratias (OPAS): de clase, empresarial y reformista. Dicha tipologia fue elaborada utilizando como criterio el de la "variable hegemónica» presente en el discurso ideológico de las distintas organizaciones, entendiéndose por hegemónica aquella que informase a otras variables tales como la filosofía reivindicativa, la estructura organizativa, las características socioeconómicas de sus bases sociales, etc. En el sindicalismo «de clase», el discurso ideológico de las organizaciones así tipificadas se caracteriza por una concepción clasista de la sociedad rutal, es decir, por entender que los agricultores familiates constituyen una clase social diferenciada - la clase campesina- de la de los empresarios agrícolas, debiendo por ello articular sus intereses en organizaciones separadas. El sindicalismo «empresarial» homogeneiza a todos los agticultores, ya sean grandes o pequeños, al consideratlos como empresarios que han de defender sus intereses en una sola organización profesional. Finalmente, el sindicalismo «reformista» no parte de una concepción clasista de la sociedad rural, si bien acepta la diversidad de problemáticas existentes entre grandes, pequeños y medianos agricultores, abogando por medidas de carácter reformista que corrijan los efectos perjudiciales del sistema económico sobre los grupos menos favorecidos, pero sin cuestionar la base estructurä de dicho sistema. Un análisis de cada tipo, así como de la génesis y desarrollo de las distintas organizaciones existentes en España, puede verse, además de en la tesis doctoral ya citada, realizada por E. Moyano, en los artículos de este mismo autor: «El sindicalismo agrario en España: las OPAS», «Revista de Extensión Agraria», vol. XXII, núm. 2, marzo-abril, 1983, pp. 33-41 y *Acciones e instituciones para una transformación de la sociedad rutal española", «Documentación Social», núm. 51, abrit-junio, 1983, pp. 125-143. 
ticias; $y$, finalmente, se establecieron algunos mecanismos de cietta rigidez sobre la forma de llevar a cabo, en la práctica, la reptesentación de cada organización o entidad participante.

En la designación de los actores puede afirmarse que el Gobierno jugó la importante baza del reconocimiento como interlocutores del sector agratio a unas organizaciones en detrimento de otras, especialmente de las sectoriales, con lo cual fue un fundamental elemento de corporatización del sector en la dirección más acorde con sus objetivos políticos y económicos.

En tercer lugar, una cuestión clave sobre las negociaciones de precios agrarios ha sido el lugar de su celebración, ya que es un indicador, junto con el status de la persona que las presidia, del rango que dichas teuniones tuvieron. En efecto, las negociaciones de 1978 y 1979 se celebraron en Ia sede del Miristerio de Agricultura y fueron presididas por el propio ministro, por lo que se denominaton «mesas» negociadoras o "pactos» de Atocha. Estas dos negociaciones han sido las de mayor rango de las celebradas, ya que significaron verdaderos encuentros corporatistas entre la gran corporación estatal, representada por su ministro de Agricultuta, y las diversas corporaciones representativas del sector agrario, en los cuales se abría la posibilidad de ampliar el conjunto de temas a debatit a cuestiones que trascendían el ámbito de los precios agtarios. La designación del Consejo General del FORPPA, a partir de 1981, como sede habitual de las negociaciones de precios agrarios redujo el rango de las telaciones entre las OPAS y el Ejecutivo al trasladarlas a un organismo específico de la Administración, ya que ello suponía limitar el campo de la negociación y, por tanto, los acuerdos adoptados, a los temas de estricta competencia del mismo.

En cuarto lugar, tal vez la cuestión de mayor complejidad, está el con. tenido de las negociaciones y los métodos utilizados para el tratamiento de los temas que se debatieron en ellas. En general, puede afirmarse que el contenido fundamental de las citadas negociaciones entre el Ejecutivo y las OPAS ha sido la determinación anual de los precios de los productos agrarios sometidos a tegulación oficial..$^{15}$ Sin embargo, desde el comienzo de las negociaciones en 1978, y dado que estos encuentros eran la única oportunidad que tenían las OPAS de entrar en relación abjerta con la gran corporación estatal, éstas procuraron introducir con éxito en la agenda de temas a tratar otra serie de cuestiones también relacionadas con la política agraria pero que trascendían los estrechos límites de la política de precios,

15. Los productos regulados son aquellos en los que interviene el FORPPA mediante algún tipo de precios. Durante el período considerado, el número de productos sometidos a regulación oficial ha sido de 19 , salvo alguna excepción, repre- 
entrando, en cierto modo, en el terreno de la política de estructuras. De esta manera, el tema de la determinación de los precios de los productos agrícolas regulados estuvo acompañado en todas las negociaciones habidas por el de la negociación de las denominadas «medidas complementarias», en las que se incluían cuestiones tales como el control de la subida de precios de los inputs agtarios, la creación de comisiones para supervisar y agilizar las intervenciones que realiza el FORPPA sobre productos no regulados, como los hortofrutícolas, la elaboración de reglamentos de determinados sectores productivos, la creación de comisiones de seguimiento para garantizar el cumplimiento de lo negociado, o cuestiones relacionadas con la necesaria teforma de la Seguridad Social Agraria.

Hacer referencia a la forma en que han sido tratados los temas que se debatían en estas negociaciones significa entrar de lleno en el problema del método. Desde el comienzo de las reuniones OPAS-Ejecutivo, en 1978, la reivindicación fundamental de las organizaciones agrarias fue eliminar el tradicional sistema de tratamiento de la problemática de cada producto de forma escalonada y su sustitución por un tratamiento global de la situación del sector agrario. A pesar de ja imposibilidad real de utilizat el método «objetivo», que es el que se aplica en 1 la $C E E,{ }^{16}$ por las deficiencias de la red contable española, las OPAS lograron que en las negociaciones se hiciese un tratamiento global de la problemática del sector agtario utilizando para ello el llamado método del "cuadro macroeconómico», consistente en estimar el cuadro macroeconómico previsto para el año siguiente y a partir de ahí determinat el incremento promedio de precios del conjunto de productos regulados y distribuirlo, de forma ponderada, entre cada producto de acuerdo con su específica situación. La introducción del tratamiento global de la problemática del sector agrario tuvo gran importancia para las OPAS, ya que en la negociación previa sobre el cuadro macroeconómico radicaba su fuerza al mostrar a la Administración, con el argumento de las cifras, la situación de crisis del sector. Si no hubiera existido esta negociación previa no les habría sido posible plantear la rea-

sentando más del $70 \%$ de la producción final agraria. Cada producto tiene un tipo de regulación diferente, si bien puede señalarse como mecanismo general el de establecer niveles de intervención inferior y superior para garantizar unos precios mí. nimos a los agricultores y evitar una repercusión excesiva en el consumidor, respectivamente, no dejando la determinación de los precios agrarios al tibre desenvolvimiento de las leyes de oferta y demanda.

16. El método «objetivo» consiste en considerar una «explotación tipo viable» y, según los datos de la Red Contable, estimar el porcentaje global que deben subir los precios agrarios para que siga siendo viable o consiga una determinada renta anual. 
lidad global del sector agrario sino que se hubiera becho un planteamiento parcial, individualizado producto a producto, omitiéndose las mactomagnitudes, que son las que muestran de forma más nítida el estado de la cuestión.

\subsection{ASPECTOS ECONÓMICOS DE LA DINÁMICA QUE TIENE LUGAR EN LAS NEGOCIACIONES DE PRECIOS AGRARIOS}

Las negociaciones de precios agrarios han sido el lugar del corporatismo agratio donde se ha venido manifestando con mayor claridad el fenómeno de subordinación de la agricultura en el sistema económico genetal. No es posible captar en su totalidad la dinámica que ha tenido lugar en el seno de esas instituciones corporatistas si no se consideran los factores de tipo económico que han estado presentes en las relaciones entre las OPAS y el Ejecutivo, condicionando, en gran medida, sus posiciones y sus fuerzas negociadoras. Por ello, es de gran importancia plantear los aspectos económicos de la negociación entre ambas partes.

Por un lado, hay que tener en cuenta que, tras la apariencia de una postura homogénea por parte de la Administración, en las negociaciones se oculta una fuerte disputa entre los diversos ministerios implicados, que no es más que expresión del conflicto de intereses entre los distintos sectores económicos y del papel regulador ejercido por el Estado. Esta disputa se planteaba, por lo general, previamente a la negociación con las OPAS y tenía hugar en la Comisión Delegada del Gobierno para Asuntos Económicos, en donde los Ministerios de Economía y Hacienda imponían al de Agricultura un cierto nivel de incremento global de precios agrarios al que debía ajustarse la posterior negociación con las organizaciones de intereses. Eran los grandes objetivos de Política Económica marcados por el Ministerio de Economía - control de la inflación, freno al desempleo, reestructuración de sectores en crisis--, los que actuaban como principales determinantes del máximo incremento global de precios agrarios que la Administración estaba dispuesta a aceptar en la negociación. En esa disputa previa se ponía ya de manifiesto la posición subordinada del sector agratio ante los otros sectores en el matco general de la política económica. De acuerdo con esta situación, los representantes de la Administración procuraban, en la negociación de las OPAS, utilizas una diversidad de argumentos, sobre la base del importante instrumento que las estadísticas oficiales representan en la elaboración del «cuadro macroeconómico», para justifi. car y sacar adelante el objetivo previsto por el Gobierno. En resumen, las negociaciones de precios agrarios se iniciaban ya con un importante condi- 
cionamiento que limitaba considerablemente el campo de to negociable y los grados de libertad de los negociadores, en lo que se refiere al tema de los precios agratios, por lo que, en rigor, cabría catalogar a esas reuniones más como «consultas» que como «negociaciones», a pesar de que aparentemente pueda creerse esto último. ${ }^{17}$

Por otro lado, y de acuerdo con lo anteriormente señalado, resulta que la dinámica de la negociación en si misma se establecía en torno al "cuadro macroeconómico» presentado por la Adminístración y, concretamente, a la estimación de la previsible evolución que debían seguir el año siguiente las magnitudes manipulables por una política económica determinada. Sobre esa previsible evolución se entablaba, por tanto, la disputa inicial entre las partes negociadoras, ya que mientras la Administración intentaba imponer sus criterios para justificar la postetior determinación de un nivel de incremento de precios compatible con los objetivos de la política económica del Gobierno, las OPAS, por su parte, y en esta cuestión prácticamente sin importantes discrepancias entre $s i$, intentaban descalificar los argumentos esgrimidos por los tepresentantes de aquélla elaborando, incluso, sus propias estadísticas agrarias y, por tanto, su propio «cuadro macroeconómicon, pata obtener un incremento de precios más acorde con la que creían que era la situación real del sector agrario.

En tercer lugar, la verdadera dinámica negociadora se producía cuando una vez determinado, con mayor o menor aceptación por parte de los participantes, el incremento promedio del nivel de precios se procedía a su distribución entre los productos tegulados. En esta cuestión radicaba la mayor intensidad de la negociación por cuanto existía un númeto mayor de grados de libertad tanto por parte de la Administración como de los representantes del sector privado y las posturas negociadoras de ambas partes podían mostrar mayor flexibilidad que en la fase anterior.

En las propuestas de la Administración sobre dicha distribución del incremento promedio de precios han influido factores económicos de diversa indole. Así, el Ministerio de Economía procutaba que fuese más pequefío el incremento de precios en aquellos productos con mayor incidencia en la "cesta de la compra» - -trigo (pan), remolacha (azúcar), aceites y carnes-, dada su tepercusión en el IPC, no preocupándole que en el resto de productos se aprobasen incrementos de precios superiores, incluso, al nivel promedio. Los representantes del Ministerio de Hacienda, por su parte, orientaban su actitud en la negociación guiados por lo que esos

17. Un detenido análisis sobre los tipos de telaciones entre los grupos de presión y los cuexpos gubernamentales, distinguiéndose entre «negociaciones» y «consultas», puede verse en H. Eckstein, Pressure Grokp Politics (Londres: Allen and Unwin, 1960), especialmente el cap. 1, pp. 15-39. 
incrementos de precios iban a representat ai Tesoro Público. En la actitud de los representantes del Ministerio de Agricultura, Pesca y Alimentación intervenían elementos de racionalidad técnica y económica. Por ejemplo, procuraban que no se desequilibrase en exceso la relación oferta-demanda en los diversos productos, no admitiendo, por tanto, incrementos altos en productos claramente excedentarios para evitar que aumentase su superficie de cultivo y, por ende, su oferta.

Desde el lado de las OPAS puede decirse que ha existido clara conciencia de que no había posibilidad alguna de modificar los planteamientos de la Administración respecto al incremento promedio del nivel de precios agratios. La escasa consolidación de sus estructuras organizativas, su bajo nivel de implantación y su dispersión y heterogeneidad son elementos que explican la debilidad negociadora de las OPAS, a los que habría que añadir su dificultad, por la peculiaridad de la actividad agrícola, para mantener una actitud firme de presión en defensa de sus reivindicaciones. Todo ello, junto con la composición de las «mesas» negociadoras en las que los representantes de las OPAS estaban en franca minoría y, en el mejor de los casos, siempre la Administración era mayoritaria frente al sector privado, ${ }^{18}$ ha hecho que el objetivo negociador de las OPAS haya estado centrado en infuir en la distribución del iacremento promedio entre cada producto. En este tema surgian importantes discrepancias, como se verá más adelan. te, dado que las características socio-económicas de las bases sociales a quienes cada OPA representaba hacían que estuviesen especialmente sensibilizadas en la problemática de aquellos grupos de productos que son la base del tipo de agricultura que aspiran a defender. Así, Ia situación de la oferta y la demanda en cada producto, la evolución de sus costes de producción y la situación del nivel de los precios de mercado en comparación con el de los precios de regulación, plantean problemáticas específicas para cada producto sobre las que varía la sensibilidad de unas organizaciones a otras, al ser variable la repercusión del incremento de sus precios en sus respectivas bases sociales.

Finalmente, un aspecto económico fundamental de las negociaciones ha sido el relacionado con las denominadas «medidas complementarias», de las que ya se ha hecho referencia. Sobre este tema sí que se entablaba una verdadera negociación entre la Administración y las OPAS especialmente,

18. Desde la institucionalización de las negociaciones con su traslado al FORPPA, las sucesivas mesas negociadotas han estado constituidas por quince representantes de la Administración y catorce del sector privado, de los cuales cinco correspondían a las OPAS y los nueve restantes a la representación de las Cámatas Agrarias y de Comercio, Cooperativas, Sociedades Agrarias de Transformación, Agrupaciones de Ptoductores Agrarios, Industrias Agtoalimentarias, Amas de Casa y Consumidores. 
manteniéndose, por lo general, al margen el resto de los participantes. Dado el carácter de «cajón de sastre» de dichas medidas, en donde puede caber todo y no caber nada, las OPAS intentaron compensar por esa vía lo que no podían lograr por vía precios. Así, cada organización, de acuerdo con su peculiar visión de la política agraria y su específica sensibilización sobre los diversos aspectos de la problemática del sector, procuraba introducir en este capítulo un conjunto de medidas que «complementasen los incrementos de los precios agrarios y se tradujese en compensaciones económicas a los grupos de agricultores que representaban. A través de estas medidas, las negociaciones trascendían el ámbito de la política de precios para entrar en el terreno de la de estructuras $y$, en ocasiones, incluso en cuestiones que escapaban a la propia política agraria, como ha sido el caso de los temas relacionados con la Seguridad Social Agraria.

La inclusión de las «medidas complementarias» en las negociaciones entre el Ejecutivo y las OPAS puede decirse que ha sido una conquista de estas últimas y el carácter de «cajón de sastre» de esas medidas ha constituido, en cierto modo, una baza negociadora importante de las organizaciones. Por estas razones, tras el lapso negociador de 1980, explicado, entre otras cosas, por el flagrante incumplimiento de las medidas negocia. das el año anterior, el Gobierno aprovechó el mandato parlamentario de institucionalizar sus telaciones con las OPAS y trasladó, como se ha señalado, las negociaciones al seno del FORPPA, con lo que reducía el rango decisotio de lo acordado en ellas y acotaba el conjunto de temas que podían ser incluidos entre las «medidas complementarias». En esta xueva situación, la actitud de los representantes de la Administración en el tema de las «medidas complementarias» ha estado condicionada por el peso que dichas medidas representaban, en términos económicos, al Ministerio de Hacienda, que era el que imponía el «techo» máximo a su cuantía global.

La polémica fundamental que ha estado presente en el período considerado, no sólo entre OPAS y Ejecutivo sino en aquéllas entre sí, sobre el tema de las «medidas complementarias», se ha centrado en el cumplimiento de las medidas acordadas en las negociaciones. A difetencia de los acuerdos sobre los incrementos de precios de los productos regulados, que eran tápidamente aprobados, parcial o totalmente, en el Consejo de Ministros siguiente a las negociaciones y tenían aplicación inmediata y tangible para los agricultores, el cumplimiento de las «medidas complementarias» acordadas dependía de la voluntad de la Administración, concretamente del Ministerio de Agricultura, y de la supervisión y seguimiento que las OPAS podían realizar a lo largo del año. Tras la experiencia de las dos primeras negociaciones en las que el grado de incumplimiento de las «medidas complementarias" fue muy elevado, las OPAS procuraron que cada 
medida acordada estuviese acompañada de la creación de la correspondiente comisión de seguimiento y del establecimiento de plazos para su cumplimiento por parte de la Administración. No obstante esta exigencia de las OPAS, la realidad ha sido que los escasos recursos organizativos de éstas han dificultado, en gran medida, que en la pràctica pudiesen llevar a cabo un firme seguimiento y un control de las medidas acordadas. De esta maneta, la importante baza negociadora que representaba para las OPAS la inclusión de las «medidas complementarias» perdía eficacia a la hora de hacerlas cumplir, to que ha sido causa de no pocos conflictos entre las organizaciones e, incluso, en el seno de cada organización. Conflictos motivados por los diferentes puntos de vista sobre la converiencia de basar la posturz negociadora ante la Administración en la conquista de medidas de difícil cumplimiento, en perjuicio de aumentar la presión sobre el logto de inctementos mayores en los precios de los productos agrarios.

\subsection{ASPECTOS SINDICALES Y POLÍt'TICOS DE LAS NEGOCIACIONES}

Las diversas estrategias utilizadas por la Admínistración en sus relaciones con las OPAS y la diferente actitud de éstas ante el conjunto de temas que componen las negociaciones, sólo pueden ser explicadas en su totalidad si se hace, adernás de los anteriores, un análisis político y sindical de las mismas. En las líneas que siguen se procederá a exponer los aspectos sindicales y políticos que subyacen en cada negociación, utilizando para ello una dimensión temporal para ir viendo el contenido cambiante de la dinámica que ha tenido lugar entre las OPAS y el Ejecutivo. Entre estos aspectos se comentatán aquí los relacionados con: a) el intervencionismo estatal en dichas instituciones corporatistas de negociación; $b$ ) la murua legitimación entre las OPAS y el Ejecutivo; c) la dispersión y diferenciación sindical de las OPAS participantes, y d) la institucionalización de las negociaciones y las formas de interferencia corporatista.

a) Como se ha señalado anteriormente, las negociaciones de precios agratios entre las OPAS y el Ejecutivo se iniciaron en febrero de 1978, bajo la presidencia del ministro Martínez de Genique, como resultado de los Pactos de la Moncloa. Desde entonces, sobre todo en las de 1978 y 1979, el intervencionismo estatal en esas instituciones corporatistas de negociación ha sido manifiesto y ha constituido un elemento de gran importancia para comprender la dinámica que en ellas ha tenido lugar.

Las negociaciones de 1978 y 1979 pueden ser consideradas como «obras personales» del ministro de Agricultura, Lamo de Espinosa. En 
efecto, cuando entró en el citado Ministerio, en mazzo de 1978, trasladó las recién comenzadas negociaciones de precios desde el FORPPA, donde se iniciaron, a la sede ministerial, recibiendo por ello el calificativo de «mesas o pactos de Atocha». Su objetivo fundamental era lograr con esas. negociaciones un verdadero impacto ante la opinión pública y, especialmente, ante la clase política, mostrando el modelo de cómo debía llevarse a cabo ese tipo de relaciones con las organizaciones de intereses para sacar adelante, de forma negociada, los importantes y, al mismo tiempo, conflictivos temas de política agraria. Para ello rodeó de espectacularidad la negociación, a la que dio amplia difusión en los medios de comunicación, y seleccionó detenidamente las relaciones con las OPAS convocadas. En esta etapa inicial del sindicalismo agrario, las organizaciones de intereses hegemónicas en el sector eran la COAG y la CNAG, por lo que basó en éstas. toda la dinámica negociadora, habiendo incluso legado a acuerdos con ellas previamente a la celebración de las negociaciones de precios, a fin de culminar con éxito dichas negociaciones.

Las negociaciones de 1979 fueron planteadas de forma similar por el ministro de Agricultura y también se celebraron en la sede de dicho Ministerio. Sin embargo, la dinámica de las relaciones con las OPAS cambió sustancialmente por parte del ministro, como consecuencia de lo que tepresentó la celebración entre ambas negociaciones de las elecciones a: Cámaras Agrarias, que tuvieron lugar a fines de mayo de 1978. Dada esta situación, las negociaciones de 1979 se caracterizaton por una dinámica diferente a las anteriores; ya no se basaton en los pactos con la CNAG y la COAG sino que la ausencia de éstos posibilitó otros nuevos y la aparición del protagonismo del resto de las organizaciones participantes, es decir, del CNJA, que repetía la participación, y de UFADE y FTT, que asistieton por primera vez.

En el año 1980 no hubo negociaciones propiamente dichas sino que las OPAS integradas en el denominado "Frente Agrario" - compuesto por CNAG, CNJA, UFADE y FTT - fueron convocadas a unas «mesas consultivas» en la sede del FORPPA para determinar los incrementos de los precios agratios de forma escalonada, sin negociación global previa del «cuadto macroeconómico». El alto grado de incumplimiento de las «medidas complementarias» acordadas en las negociaciones del año anterior, el elevado incremento de los precios de los inputs producido y el bajo nivel de incremento general de precios agrarios impuesto por el Ministerio de Economía al de Agricultura, explican, en gran medida, el interés del ministro Lamo de Espinosa para evitar la celebración de unas negociaciones que se vaticinaban intensamente conflictivas. $\mathrm{Si}$ a los hechos anteriores se unen la debilidad real de las OPAS, tras el auge de la etapa inicial, y el am- 
biente sindical, especialmente tenso por las movilizaciones promovidas por la COAG en protesta contra, y para contrarrestar, el «Frente Agrario» formado por el resto de las organizaciones, se obtiene un amplio cuadro explicativo del cambio en la estrategia del Ejecutivo ante las OPAS y la impotencia de éstas para oponerse al mismo. En 1980, por tanto, sólo hubo consultas entre la Administración y algunas OPAS y no una negociación global sobre la problemática del sector agtatio, lo que se tradujo, en la práctica, en un incremento sensiblemente más bajo que los años antetiores en el nivel general de los precios agtarios y la ausencia de compromisos sobre «medidas complementarias».

A partir de la moción presentada por la oposición en el Pleno del Congreso de los Diputados del 24 de octubre de 1980, y asumida parcialmente por el Gobierno, se promulgó el decreto de reestructuración de los órganos de gobierno del FORPPA - Consejo General y Comité Ejecutivo y Financiero- y se acordó trasladar, de forma definitiva, las negociaciones entre las OPAS y el Ejecutivo al seno de dicho organismo autónomo de la Administración, institucionalizándolas e introduciendo en eilas la interferencia de nuevos grupos participantes. Desde ese momento, en los años 1981 y 1982 se celebraron con normalidad en el FORPPA las negociaciones de precios agrarios y «medidas complementarias» en el seno de la denominada Comisión Especializada, equivalente, en cuanto a su composición, al Consejo General del FORPPA, dado el temor por parte de la Adrninistración de que las impugnaciones presentadas a la composición de dicho Consejo invalidaran los posibles acuercos tomados en el mismo. Como se ha seña. lado, la nueva orientación de las negociaciones significó una nueva dinámica en la que ha estado ausente el protagonismo personal del ministro de turno, como se puso de manifiesto en las celebradas en 1982, a pesar de que poco tiempo antes de las mismas se había producido un cambio ministerial.

b) Una valoración político-sindical de las negociaciones celebradas en el período considerado tras el oportuno análisis del contenido de los discursos emitidos por las diversas organizaciones agrarias participantes, permite afurmar que su dinámica ha descansado, fundamentaimente, en la legitimación mutua que dichas negociaciones han representado para el Ejecutivo y para las OPAS. Desde el lado del Ejecutivo, las negociaciones han significado una forma de legitimat su política agratia en una etapa de transición política desde un régimen autoritario a otro democrático, en la que, precisamente, el partido encargado de dirigir el proceso de teforma ha estado constituido por personas y grupos estrechamente vinculados al antetior régimen $y$, por tanto, necesitados de legitirnar socialmente las nuevas directrices de su política. Esta necesidad de legitimación social por 
parte del Ejecutivo ha estado, aunque no exclusivamente, en la base explicativa de mantener unas negociaciones con las OPAS, que si bien fueton iniciadas por mandato de los Pactos de la Moncloa también es cierto que pudieron no establecerse, dado que la firma de tales pactos no significaba una fuerte autoridad pata su cumplimiento, como ocurrió con otras cuestiones acordadas en ellos.

Por parte de las OPAS ha sido unánime el reconocimiento de su débil posición negociadora en dichos encuentros con el Ejecutivo y de la escasa capacidad de influencia en unas cuestiones relacionadas con la política de precios, sobre las que previamente existía un importante condicionamiento por parte de los objetivos generales de la Política Económica. Sin embargo, también ha sido unánime la necesidad de participar en ellas por cuanto esas negociaciones constituían una fundamental razón de ser ante sus bases sociales y, tal vez, la única oportunidad de aparentar erigirse en grupos de presión en los centros de decisión desde donde fluye la política agtaria del país. Además, las negociaciones han sido la motivación principal para que las OPAS estudiasen en profundidad la problemática agrícola española y conociesen los planteamientos económicos de los que elaboran la política agraria, así como ban sido ocasiones para que los agricultores participasen directamente en la tesolución de los problemas que les afectan.

c) Las posiciones de las OPAS ante los temas que se han debatido en las negociaciones de precios agrarios se diferencian entre sí de acuerdo con sus especíicas filosofías reivindicativas. En efecto, las diferencias profundas en las filosofías reivindicativas y formas de concebir la política agraria que existen entre los sindicalismos «de clase», «empresarial» y «teformista» tienen su reflejo en las respectivas actitudes mantenidas en las mesas negociadoras celebradas en el período considerado. Sin embargo, debe tenerse en cuenta que, aunque hay elementos lo suficientemente comunes en los discursos de las OPAS para establecer la tipología anterior, en la práctica negociadora la dispersión ha sido mayor, ya que, además de las diferencias profundas de tipo ideológico a las que responde con cietto rigot la citada clasificación, se ha producido en esa dinámica la inevitable competencia entre organizaciones de un mismo tipo de sindicalismo con el objetivo de consolidar o actecentar su influencia en él, en perjuicio de la que poseía Ia organización competidora. Así, no puede hablatse de una posición única del sindicalistno «de clase», puesto que las actitudes de COAG y FTT han variado en la dinámica negociadora y no han planteado, previamente, una estrategia sindical común como pudiera creerse dadas sus reales afinidades ideológicas. Lo mismo puede decirse en el caso del sindicalismo "teformista», aunque con ciertos e importantes matices, dado 
el permanente proceso de aproximación y alejamiento entre el CNJA y UFADE, así como sus intensos personalismos, que han hecho variar sus actitudes y estrategias negociadoras según el estado de sus relaciones interorganizativas. El caso «empresatial agrícola» ha sido más simple por cuanto ha participado en las negociaciones representado, exclusivamente, por la CNAG, cuya hegemonía es indiscutible en este tipo de sindicalismo.

Sin entrar en las diferentes filosofías reivindicativas de las OPAS, se hará una serie de comentatios sobre sus respectivas actitudes en la dinámica negociadora.

En el sindicalismo «de clase», la COAG mantuvo la hegemonía negociadota desde su participación en la primera negociación de 1978 y ha tepresentado el apoyo fundamental utilizado por la Administración para sacar adelante las sucesivas negociaciones. Su elevado nivel de implantación en zonas importantes de agricaltura familiar y la firmeza y claridad de su filosofía reivindicativa, basada en una política de rentas cuyo eje fueran las «medidas complementarias», aunque sin olvidar la necesaria política de precios, han sido factores que han resultado compatibles con los objetivos políticos y econónicos del Ejecutivo. Así, la aceptación, por parte de la COAG, conno hecho inevitable, que la tecuperación del nivel de rentas de los agricultores no puede lograrse por vía precios, de acuerdo con la lógica del sistema económico, y su convicción de que la política de precios es siempre discriminatoria para los agricultores familiares, les ha llevado a plantear sus objetivos negociadores en el terreno de las «medidas complementarias», con lo que dejaba de constituir una amenaza, y sí se conveztía en un apoyo, al objetivo del Ejecutivo de que el incremento general de los precios agratios no traspasara el techo impuesto por el Ministerio de Economía. ${ }^{19}$

De acuerdo con lo que entiende como intereses de la agricultura familiar, la COAG, en el tema de la distribución del incremento general de precios entre cada producto regulado, ha procurado conseguir mayores aumentos en aquellos productos que son más básicos para ese tipo de agticultura, como el algodón, el maíz, la leche, el vino, etc., reivindicando, constantemente, la inclusión entre los tegulados de los productos hortofrutícolas, que son la base, en muchas zonas, de los agricultores familiares.

La ausencia de una clarificación interna sobre su flosofía y estrategia sindicales, a caballo entre los trabajadores agrícolas y los pequeños agricultores, ba conducido a la FTT a mantener una actitud pasiva, como a la

19. Prueba de ello es que en las negociaciones en las que participó la COAG siempre aprob6 los acuetdos finales, lo que no siempre ha ocurrido con el resto de las OPAS. 
defensiva, en las negociaciones. Sus reivindicaciones apenas se han diferenciado de las de la COAG y sus distintas actitudes han sido, tal vez, tesultado de estrategias para afrmar una cierta diferenciación organizativa y sindical respecto de esa otra organización, que no de distintas concepciones sobre lo que debía ser la política agraria más beneficiosa para la agricultura familiar. Por razones similares a lo antes señalado para la COAG, a las que habría que añadit la posible influencia de la política de consenso mantenida entre el partido del Gobierno de UCD y el PSOE, la FTT no ha sido nunca obstáculo para que saliertan adelante las negociaciones de acuerdo con los planes del Ejecutivo.

El comportamiento del sindicalismo «empresarial», tepresentado por la CNAG, en las negociaciones de precios agratios ha sido de gran claridad, dentro de su peculiar flosofía reivindicativa y de su creciente aproximación a los planteamientos económicos de la CEOE. La actitud general de la CNAG ha sido la de plantear las negociaciones en torno a la política de precios y en considerar secundarias las "medidas complementarias», reivindicando un incremento general, que si bien era fiel reflejo de la situación del sector, justificada con sofișticados argumentos y estudios técnicos, era, sin embargo, inaceptable en los planteamientos de Política Económica desde los que partía la Administración y hacía omisión de la tepercusión discriminada que tales incrementos tendrían, caso de aprobarse, entre los distintos tipos de agricultores. En este sentido, han sido sus reivindicaciones de incremento general de precios, las más alejadas de las propuestas por la Administración y por el resto de las OPAS. Respecto a la distribución del incremento general entre los diversos productos el interés fundamental de la CNAG se ha centrado en el logro del mayor incremento de precios posible en cultivos extensivos como cereales, aceite de oliva, remolacha o girasol, entre otros, que son la base del tipo de agricultura dominante en ella.

Ed sindicalismo "reformista», representado por el CNJA y UFADE, se ha movido en las negociaciones con la ambigüedad propia de un sindicalismo de bases sociales muy heterogéneas, de estrechos vínculos con la anterior Administración, difícilmente desligables, y de permanente tensión por la fuerte presión organizativa a que se ha visto sometido por parte del sindicalismo «empresarial». Su actitud negociadora, por tanto, ha estado fuertemente condicionada por los demás participantes, ya que tenían la permanente necesidad de diferenciar su posición tanto del sindicalismo «de clase» como del «empresarial». Así, su frme convicción en la defensa de la agricultura familiar les ba conducido a plantear las negociaciones sobre la base de unas «medidas complementarias» que compensasen lo que no podía conseguirse por vía precios y que reestructurasen el sector de 
cata al próximo ingreso en la $\mathrm{CEE}$, pero han debido procurar no aparecer adoptando posiciones similares a las del sindicalismo «de clase». Por ello, frecuentemente, el comportamiento de los representantes del sindicalisino "reformista» ha sufrido imprevisibles variaciones de difícil justificación como no sea introduciendo elementos explicativos del tipo de los anteriormente señalados.

d) Finalmente, hay que poner de manifiesto que en la dinámica que ha tenido lugar a partir de la institucionalización de las negociaciones con su traslado a la sede del FORPPA, concretamente a la Comisión Especializada equivalente a su impugnado Consejo General, se han reflejado con claridad algunos aspectos de la interferencia corporatista señalada anteriotmente. En efecto, la presencia en dicha Comisión de representantes de grupos distintos de los agtatios ha introducido una clara interferencia en el proceso de articulación de los intereses agrarios y en su participación, a través de las OPAS, en esas instituciones corporatistas. Así, la participación del sector industrial agroalimentario ha constituido una interferencia de tipo «interorganizativo", ya que estos representantes de estructuras corporatistas diferentes de la agratia han competido con los representantes de ésta para influir en los centros de decisión. Además, el hecho de que ambas organizaciones representativas estén integxadas en la CEOE ha añadido a la interferencia señalada otra de tipo «intraorganizativo», al producirse la competencia entre organizaciones pertenecientes a una misma estructura organizativa de rango superior, puesto que entre ellas se ha dado la mutua oposición en algunos de los temas debatidos en las negociaciones - por ejemplo, en los precios de productos industrializables como el trigo o la remolacha-, no existiendo, sin embargo, ningún tipo de estrategia común en aquellos otros que en nada, o en poco, afectan al sector agroalimenta. rio. El mismo análisis sería válido para el representante de las Cámaras de Comercio, a cuyos grupos de intereses que representa también están integrados en la CEOE.

Otra forma de interferencia, también de carácter «intraorganizativo», se ha producido entre las OPAS y los representantes de las Cooperativas (UNACO), Asociaciones de Productores Agrarios (APAS) y Sociedades Agrarias de Transformación (SAT), dado que en los grupos a los que representan existen numerosos agricultores afiliados, a su vez, a alguna de las cinco organizaciones profesionales agtarias presentes en las mesas ne. gociadoras.

Finalmente, desde el lado de la Administración, la presencia en las negociaciones de representantes de ministerios diferentes al de Agricultura ha sido la manifestación externa de una interferencia más profunda que, 
como se ha señalado, ocurre en una fase previa a las propias negociaciones en el seno de la Comisión Delegada del Gobierno para Asuntos Económicos, donde se establecían los límites económicos de la negociación entre la Administración y las otganizaciones de intereses del sector privado.

Las negociaciones entre las OPAS y el Ejecutivo sobre diversos aspectos de la política agraria han sido, en definitiva, un caso empítico de gran significación para estudiar el funcionamiento de las instituciones corporatistas de representación/mediación en la agricultura española. En ellas han podido observarse tanto los tasgos generales del corporatismo, comunes a otras esferas de la vida social, como las características peculiares que ad. quiere en la agricultura. En efecto, junto a rasgos como la reducción del pluralismo representativo, la concentración del poder en unos cuantos centros de decísión, la presencia hegemónica de grandes organizaciones de intereses o la práctica de la concertación entre éstas y el Ejecutivo, que caracterizan de forma general al corporatismo, también se han observado otros específicos del corporatismo agrario, como la mayor dispersión del panorama representativo, la menor corporatización interna de las orgatiza. ciones de intereses, Ia debilidad de estas organizaciones en el ejercicio de su influencia, la interferencia de estructuras corporatistas diferentes de la agraria o el mayor protagonismo del Estado.

Todo lo anterior configura una dinámica social que puede ser, en gran medida, explicada por el marco teórico cuyas proposiciones fundamentales han sido enunciadas en este trabajo. Su contrastación con otros casos empíricos ha de ser el objetivo de nuevas investigaciones sobre el corporatismo. 